Structural changes of silicon upon high-energy milling investigated by Raman spectroscopy

This article has been downloaded from IOPscience. Please scroll down to see the full text article.

2008 J. Phys.: Condens. Matter 20025205

(http://iopscience.iop.org/0953-8984/20/2/025205)

View the table of contents for this issue, or go to the journal homepage for more

Download details:

IP Address: 192.33.126.163

The article was downloaded on 24/10/2011 at 14:52

Please note that terms and conditions apply. 


\title{
Structural changes of silicon upon high-energy milling investigated by Raman spectroscopy
}

\author{
P Unifantowicz ${ }^{1,2}$, S Vaucher ${ }^{2}, \mathbf{M}$ Lewandowska ${ }^{1}$ and \\ K J Kurzydłowski ${ }^{1}$ \\ ${ }^{1}$ Faculty of Materials Science and Engineering, Warsaw University of Technology, \\ Ulica Wołoska 141, 02-507 Warsaw, Poland \\ ${ }^{2}$ EMPA-Swiss Federal Laboratories for Materials Testing and Research, Feuerwerkerstrasse \\ 39, 3604 Thun, Switzerland \\ E-mail: paulina.unifantowicz@empa.ch
}

Received 12 September 2007, in final form 14 October 2007

Published 6 December 2007

Online at stacks.iop.org/JPhysCM/20/025205

\begin{abstract}
This study showed pronounced changes in the Raman scattering of silicon powder during high-energy ball milling. The powders were milled for $1-18 \mathrm{~h}$ in a steel ball mill in argon. The approximate pressure imposed on particles was $2 \mathrm{GPa}$. The spectra of the as-milled powders were compared with the initial silicon. It was found from the Raman peak position shifts that milling generated strains in the silicon lattice, bringing about a transformation of cubic silicon to tetragonal silicon and amorphization. The relative amount of new phases was determined from the area under the measured Raman peaks.
\end{abstract}

(Some figures in this article are in colour only in the electronic version)

\section{Introduction}

The physical properties of materials are strongly determined by their crystal structure and the presence of defects. Therefore, it is important that the changes of the crystal structure induced by various processing routes are carefully tailored to the needs of various applications. This in particular refers to silicon, the most technologically important semiconductor material.

High-energy milling is now one of the materials processing methods that is widely used in powder technology. The advantage of high-energy milling is its simplicity and effectiveness. In addition, it can greatly alter both the surface and the bulk of a milled material. Particle and grain refinement, lattice transformation and amorphization are likely to occur. Also, the generation of dislocations and stacking faults takes place [1], as well as mechanical alloying [2]. Structural changes in various materials, including silicon, during their milling have been a subject of many investigations [1, 3, 4].

The products of milling are usually characterized using X-ray diffraction (XRD). Raman studies of silicon after highenergy milling have not been carried out so far to the best knowledge of the authors. The advantage of Raman spectroscopy over XRD analysis is that the spectra can be collected from a very small volume, even below $1 \mu \mathrm{m}$ in diameter, which is simultaneously observed using a light microscope. Also, the amorphous phase does not contribute to a background of the spectrum, thus reducing the information noise.

Raman spectroscopic studies presented in [5] showed a transformation of silicon from cubic to tetragonal, due to high loads applied during indentation tests. High-energy milling, like other non-equilibrium methods, has a potential to distort the lattice and produce amorphous silicon. In the latter, so-called coordination defects are generated which affect the electron density of states [6]. This in turn changes the dielectric and thermal properties of silicon. Amorphous silicon is nowadays a popular semiconductor, for example in photovoltaic solar cells and thin-film resistors [7].

Raman spectroscopy can be used to examine crystal structures [8] and stresses [9] and to indicate temperature changes in the investigated materials [10]. It was used here to investigate the evolution of the structure of silicon during high-energy ball milling. 
(a)

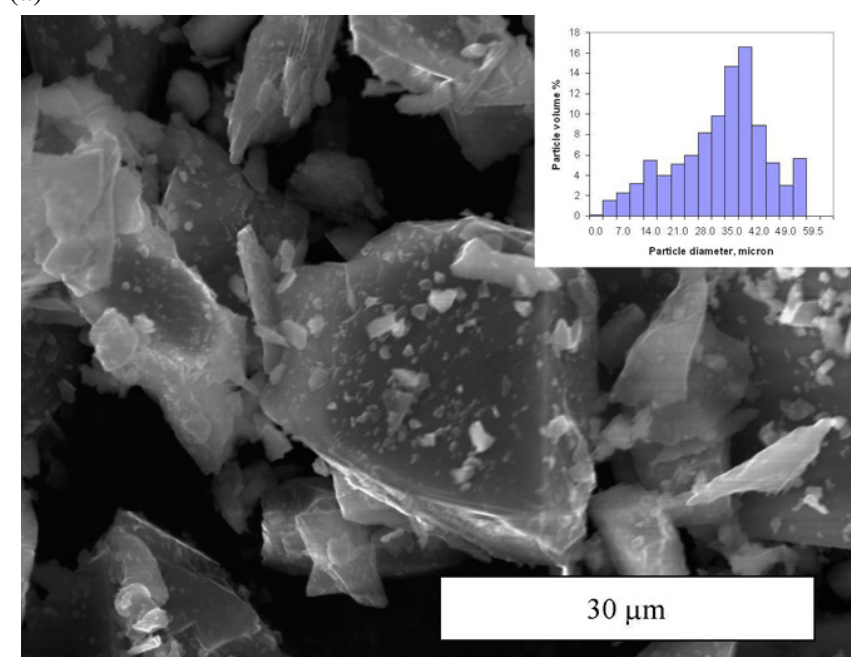

(b)

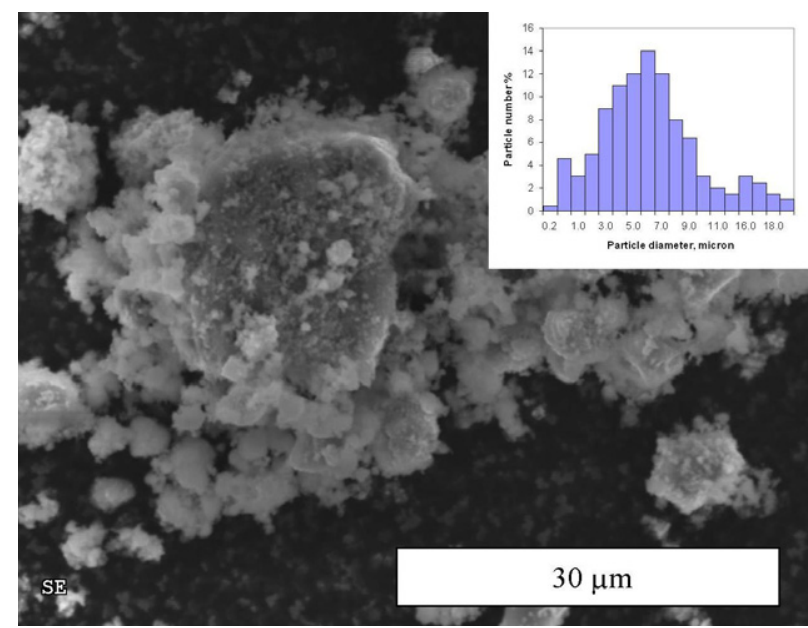

(c)

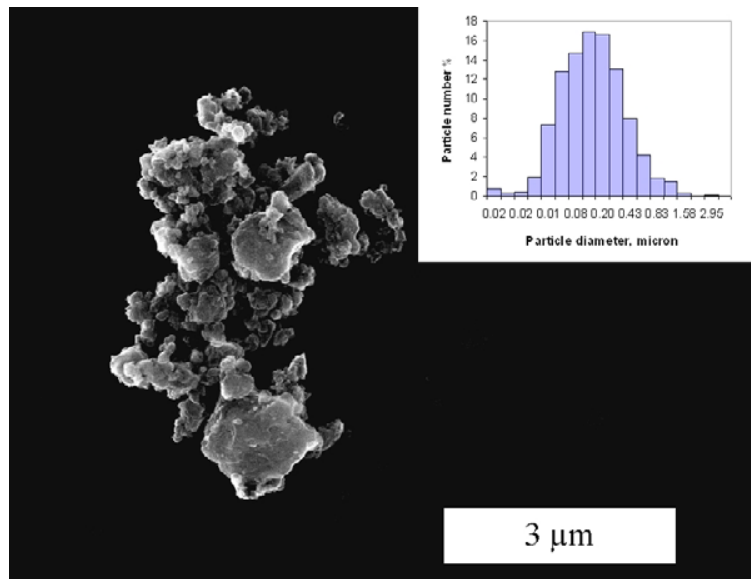

(d)

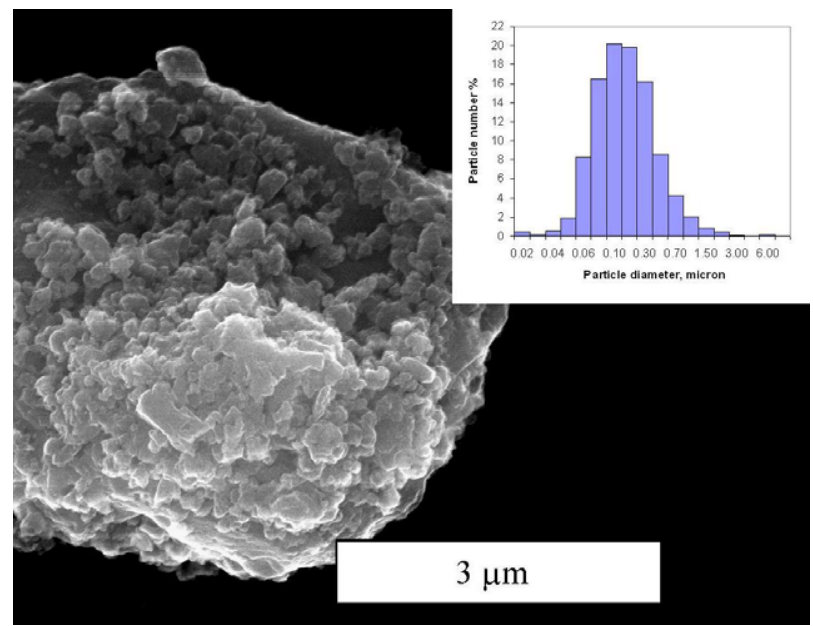

Figure 1. SEM micrographs of the investigated Si powders: (a) initial, (b) after $1 \mathrm{~h}$, (c) after $6 \mathrm{~h}$ and (d) after $18 \mathrm{~h}$ ball milling with the histograms of particle diameter $(\mu \mathrm{m})$.

\section{Experimental details}

The investigated silicon powder containing $2.3 \times 10^{17} \mathrm{~cm}^{-3}$ antimony and less than $0.005 \mathrm{wt} \%$ of iron had a mean particle diameter of $2.2 \mu \mathrm{m}$. The Si powder was produced by crushing and ball milling a monocrystal obtained using the Czochralski method and then sieving the powder. The weight ratio of balls to powder upon high-energy milling was 14.5 . The pressure imposed by the balls on $1 \mathrm{~g}$ of powder during milling was approximately $2 \mathrm{GPa}$.

The particle diameter $\left(d_{10}, d_{50}, d_{90}\right)$ of the milled and the initial silicon was measured on the basis of the scanning electron microscope (SEM) micrographs, figure 1. The obtained values are summarized in table 1 .

The Raman spectra were measured using a Renishaw Raman spectrometer of inVia type, integrated with a light microscope. The laser wavelength was $0.633 \mu \mathrm{m}$. The spectra were collected in the Raman shift range $200-600 \mathrm{~cm}^{-1}$ at a resolution of $1.64 \mathrm{~cm}^{-1}$. Calibration of the spectrometer was performed using a monocrystalline silicon wafer, setting the peak at $520 \mathrm{~cm}^{-1}$. The magnification of the microscope
Table 1. Distribution of particle diameter for the initial Si and the milled Si powders.

\begin{tabular}{|c|c|c|c|c|c|}
\hline \multirow[b]{2}{*}{ Si powder } & \multicolumn{5}{|c|}{ Grain size $(\mu \mathrm{m})$} \\
\hline & $\begin{array}{l}d_{10} \\
\text { vol }\end{array}$ & $\begin{array}{l}d_{50} \\
\text { vol }\end{array}$ & $\begin{array}{l}d_{90} \\
\text { vol }\end{array}$ & $\begin{array}{l}\text { Average } \\
\text { vol }\end{array}$ & $\begin{array}{l}\text { Average } \\
\text { no. }\end{array}$ \\
\hline Initial & 15 & 47 & 62 & 29 & 2.2 \\
\hline $1 \mathrm{~h}$-milled & 2.0 & 6.2 & 16.7 & 6.6 & 1.5 \\
\hline $6 \mathrm{~h}$-milled & 0.33 & 0.89 & 2.6 & 1.1 & 0.24 \\
\hline $18 \mathrm{~h}$-milled & 0.93 & 5.1 & 5.3 & 4.7 & 0.27 \\
\hline
\end{tabular}

objective was 50 and the time of exposure was $10 \mathrm{~s}$. The intensity of the laser beam varied between $0.18 \pm 0.01$ and $1 \pm 0.1 \mathrm{~mW}$, respectively. In order to increase the signal-tonoise ratio, a higher laser power was preferable. However, due to the low thermal conductivity of the powder beds, the Raman shifts become a function of laser power. Immersion of the powders in water prevents this thermal drift, so that reproducible Raman shifts can be collected independently of the laser power. 


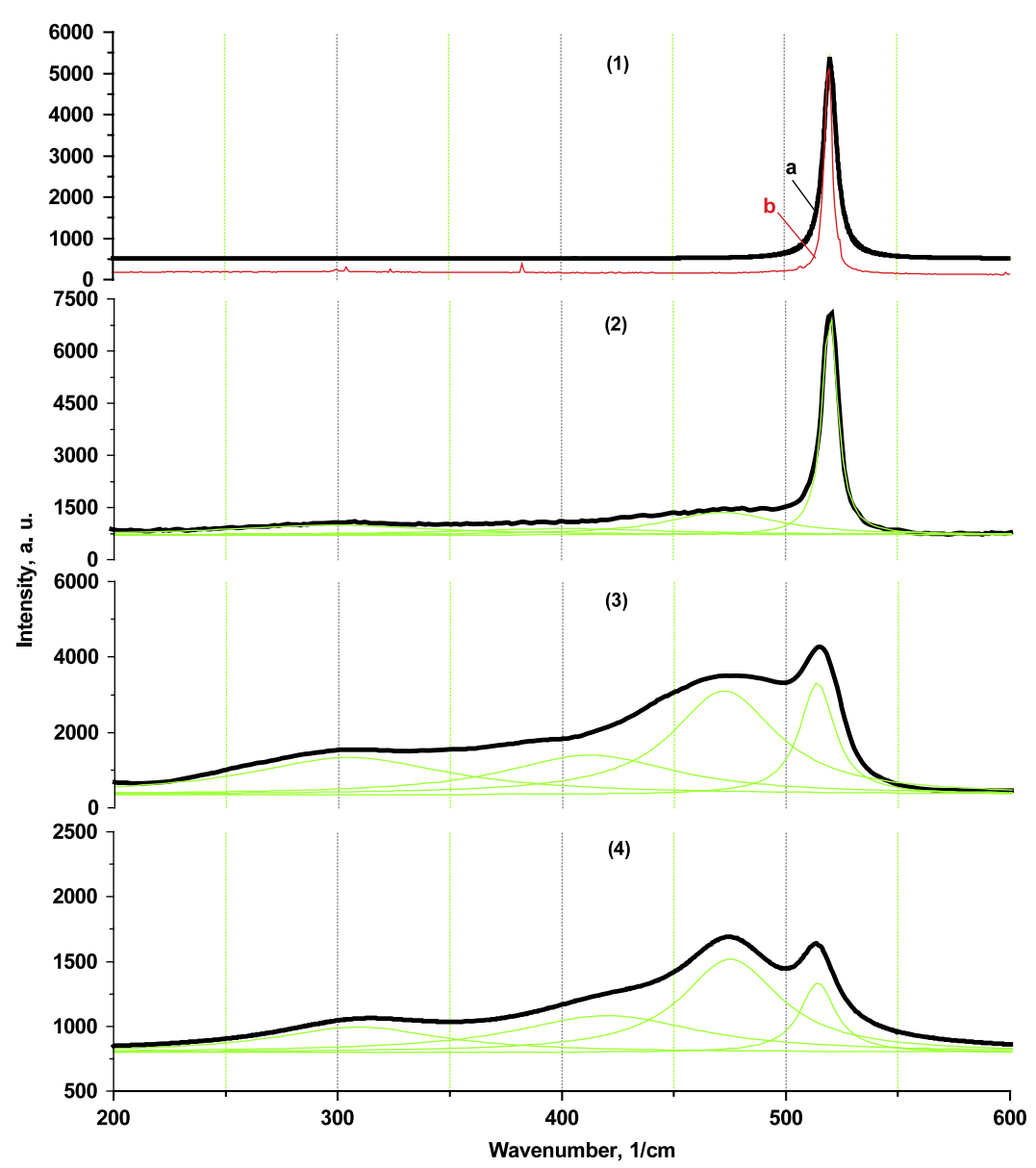

Figure 2. Raman spectra of (1a) initial Si, (1b) Si nanopowder after evaporation and condensation, (2) Si milled for $1 \mathrm{~h}$, (3) $6 \mathrm{~h}$, (4) $18 \mathrm{~h} \mathrm{with}$ Lorentz function fitted to the peaks.

\section{Results and discussion}

\subsection{Influence of high-energy milling on the Raman spectra of silicon}

Raman spectra collected for the as-received silicon powder and the powders milled for different periods of time are shown in figure 2. After deconvolution of the curves, Lorentz functions were fitted in order to obtain the individual peaks. The measured parameters (centre of the peak $X_{\mathrm{c}}$, full width at halfheight, $W$, and the area under the peak, $A$ ) are plotted as a function of milling time in figures 3(a)-(c).

The following Raman peaks characteristic for phonon vibrational modes of silicon were identified, according to reported data:

- crystalline silicon, c-Si, having face-centred cubic (fcc) diamond structure type, at about $300 \mathrm{~cm}^{-1}$ [11] and $520 \mathrm{~cm}^{-1}[8,9]$;

- crystalline silicon, t-Si, having body-centred tetragonal structure, bc 8 type, at $420-430 \mathrm{~cm}^{-1}$ [9];

- amorphous silicon, a-Si, at $470-480 \mathrm{~cm}^{-1}$ [11].

The evolution of the peak parameters with milling time, figure 3 , shows that the characteristic peak of cubic silicon, c$\mathrm{Si}$, was found at $520 \pm 2 \mathrm{~cm}^{-1}$ for all investigated samples. This represents the longitudinal optic phonon mode in silicon of cubic diamond structure [8]. Besides the c-Si, peaks of two additional phases appeared in the milled powders, i.e. tetragonal and amorphous silicon. The presence of a-Si and $\mathrm{t}-\mathrm{Si}$ peaks proved the lattice transformation of $\mathrm{c}-\mathrm{Si}$, which was expected due to the high loads imposed on the material [5]. The peak at $300 \mathrm{~cm}^{-1}$ was ascribed to transverse acoustic phonon vibrations of the defected cubic silicon, c-Si, lattice.

It was observed that the c-Si peak centre shifted toward lower wavenumbers by $6 \mathrm{~cm}^{-1}$, while the peak width increased by around $10 \mathrm{~cm}^{-1}$ for $6 \mathrm{~h}$ milled silicon; figures 3(a) and (b). The first effect indicates that the lattice has been strained, resulting in a change in the $\mathrm{Si}-\mathrm{Si}$ bond length. On the other hand, the effect of peak broadening was due to a higher discrepancy in the distribution of the bond lengths in the asmilled powder.

The shift of the c-Si peak with milling time was combined with changes of other peak positions. After $1 \mathrm{~h}$ of milling, the tSi peak and the defect-induced c-Si peak shifted toward higher wavenumbers. This was attributed to a deformation of the crystal lattice by high compressive stresses and to an increase in the density of lattice defects rather than to the refinement of the particles. It was stated in [8] that the peak found between 510 and $514 \mathrm{~cm}^{-1}$ is typical of microcrystalline silicon. However, the Raman spectrum of a nanocrystalline Si powder with a non-defected lattice, investigated by Vaucher [10], did 

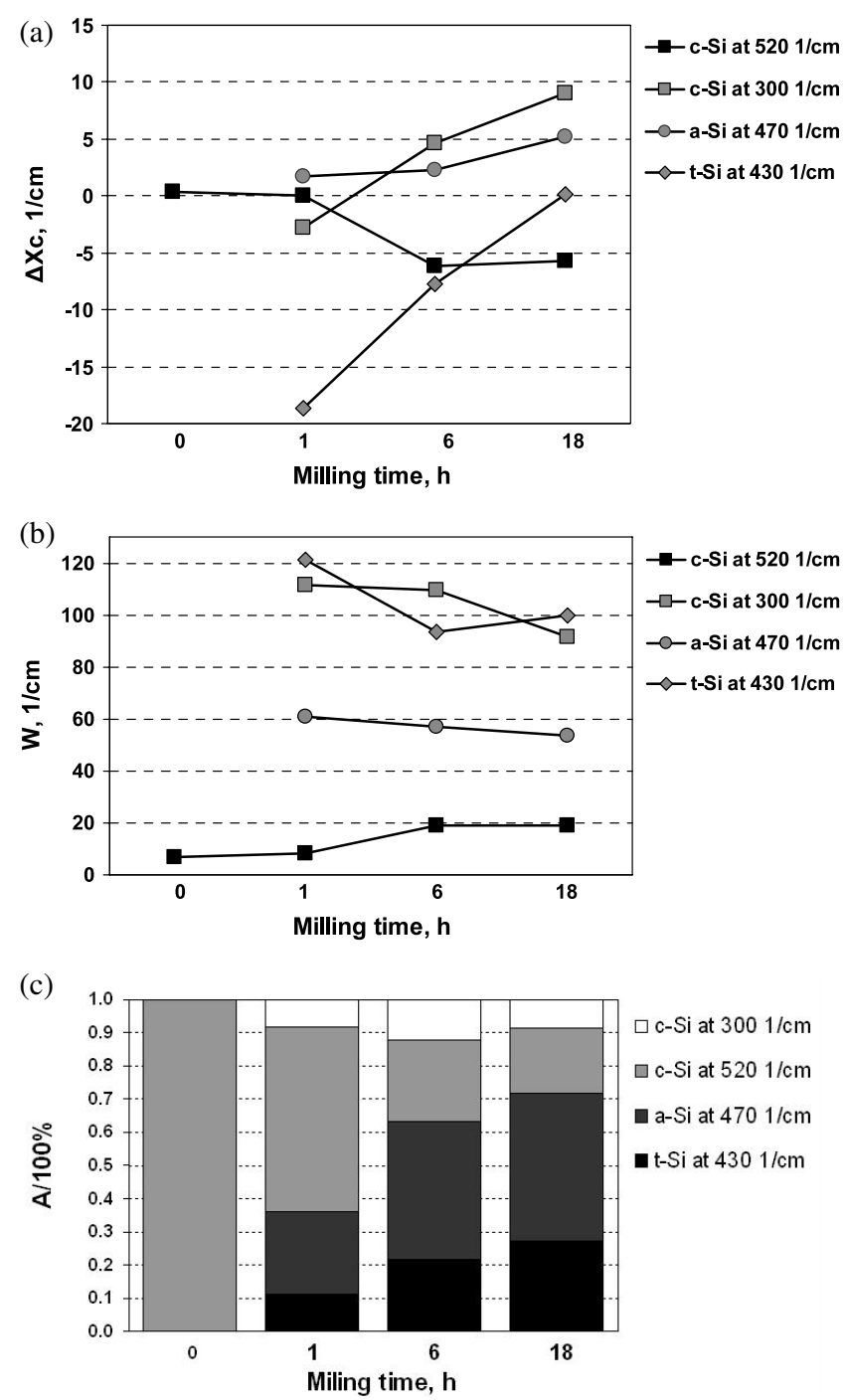

Figure 3. Raman peak parameters versus milling time for $\mathrm{Si}$ : (a) centre positions, (b) full width at half-height and (c) relative peak area.

not differ from the spectrum of the coarse-grained initial $\mathrm{Si}$ powder; figure 2 , spectrum $1(\mathrm{a}, \mathrm{b})$. Therefore, the particle size seems to have no influence on the Raman spectrum. The amorphous Si peak shifted slightly toward lower vibrational frequencies, which could be explained in terms of changes in the range of order in the amorphous structure.

Assuming that the total number of Raman scattering events gives rise to the area under the peak, the relative amount of a particular phase can be estimated. Accordingly, the peak intensity of $\mathrm{c}-\mathrm{Si}$ in the milled powders decreased compared with the initial intensity, figure 3(c), due to a decrease in the relative amount of $\mathrm{c}-\mathrm{Si}$. In contrast, for $\mathrm{t}-\mathrm{Si}$ after $6 \mathrm{~h}$ of milling there was a decrease in the peak width and a rise in the intensity. An $18 \mathrm{~h}$ milling did not significantly change the peak width. Only a small increase in the intensity, by about $7 \%$, was observed. Similarly, for the a-Si and defected c-Si, the peak widths became smaller and the peak areas rose with milling time. This is likely to be related to an increase in the relative amount of the respective phases.
The relative area under the peak, $A$, is expressed as:

$$
A=\frac{A_{n}}{\sum_{n} A_{n}},
$$

where $A_{n}$ is the absolute peak area and $n$ is the peak number.

Among the powders milled for different times, one can see that the relative area of c-Si peak decreased from $100 \%$ for the initial silicon to 40,15 and $13 \%$ for 1, 6 and $18 \mathrm{~h}$ milled silicon, respectively. This indicates that the amount of cubic silicon decreases with milling time, especially in the early stage, after $1 \mathrm{~h}$ of milling. On the other hand, the area under the tetragonal and amorphous peaks grew with milling time, while the biggest increase was observed at $6 \mathrm{~h}$. The area of the defect-induced cSi peak rose after $6 \mathrm{~h}$ of milling, which was most likely related to the increase in the number of lattice defects. However, at 18 $\mathrm{h}$ of milling, this peak was reduced by about $4 \%$, which could be due to annihilation of the defects, with regard to an elevated temperature of the powder upon milling.

\subsection{Influence of cooling on the measured Raman spectra of the Si powders}

During Raman measurement, the powder is usually heated by the laser beam focused on the surface of the material under investigation, which affects the Raman shift. The intensity of this heating depends on the thermo-physical properties, size and shape of the particles, and also on the laser power. It was observed that the lower the power that was used, the bigger the noise was that interfered in the spectra; this rationalizes the use of a high-power laser. However, high power causes heating of the powder, which affects the results of measurements. Pure water was used in the current experiments to avoid the undesirable effect of heating.

Water is an efficient heat-removing medium which is not Raman-active, thus it was used for cooling the powders during the measurements. The Raman spectrum of the as-obtained silicon powder was compared with the same powder in a drop of distilled water; figure 4 .

In the case of the uncooled powder, the position of the cSi peak shifted by about $2 \mathrm{~cm}^{-1}$ toward lower wavenumber, to $517.5 \mathrm{~cm}^{-1}$ when the laser power was increased from $0.2 \mathrm{~mW}(10 \%)$ to $1 \mathrm{~mW}(50 \%)$; figure 4(a). Peak shifts towards lower wavenumber with an increase in temperature were also observed in [12]. According to the results of Raman measurements for silicon powder given in [10], the Raman peak at $517.5 \mathrm{~cm}^{-1}$ for cubic Si corresponded to a temperature of approximately $400 \mathrm{~K}$, which seems to have a significant influence on the Raman measurements. In the case of the cooled silicon powder, figure 4(b), the peak centre position shifted only slightly, by less than $0.1 \mathrm{~cm}^{-1}$. In comparison to the uncooled powder, the powder placed in water showed smaller peak intensities.

\section{Conclusions}

It was found that Raman spectra followed the changes in the silicon structure subjected to high-energy ball milling, causing amorphization and transformation of a cubic lattice 

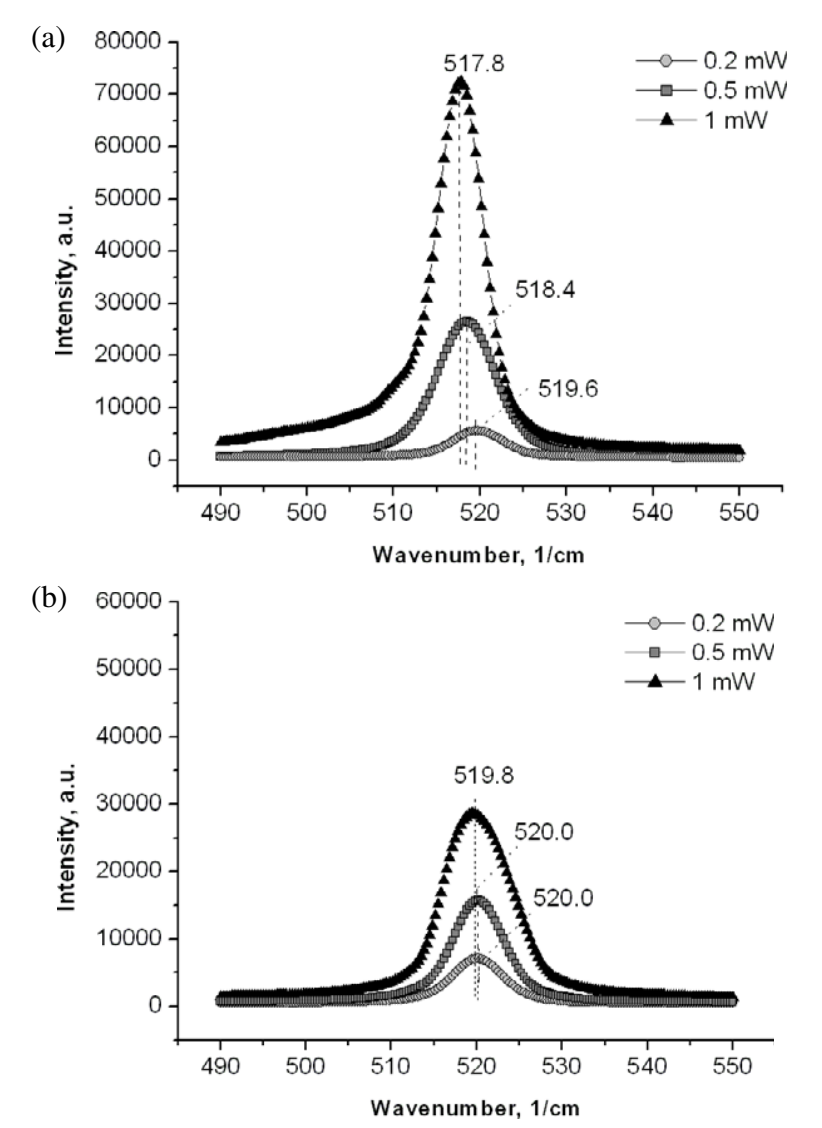

Figure 4. The influence of laser power, $P$, on the Raman shifts of initial Si powder: (a) without and (b) with cooling.

into a tetragonal lattice and the generation of lattice defects. These effects were already observed after $1 \mathrm{~h}$ of milling, while after $18 \mathrm{~h}$ the amount of a-Si and t-Si was the highest. The shifts of the c-Si peak position to lower wavenumbers indicated the change in bond vibration frequency with milling time. This was attributed to deformation of the silicon lattice, in particular to its straining and an increase in the density of defects. Water cooling during Raman measurement prevented heating of the powder by the laser beam, helping to overcome misinterpretation of the results. This resolution can be particularly advantageous in the Raman measurement of nanopowders.

\section{Acknowledgments}

The authors direct kind acknowledgements to Dr Simon Kleiner from the Materials Technology Department in Empa Thun for advice and technical support and to Dr Paul Hug from the Solid State Chemistry and Catalyses Department in Empa Dübendorf for enabling the Raman measurements.

\section{References}

[1] Streletskii A N, Leonov A V and Butyagin P Y 2001 Amorphization of silicon during mechanical treatment of its powders: 1. Process kinetics Colloid J. 63 690-4

[2] Matteazzi P, Le Caër P and Mocellin G A 1997 Synthesis of nanostructured materials by mechanical alloying Ceram. Int. 23 39-44

[3] Shen T D, Koch C C, McCornick T L, Nemanich R J, Huang J Y and Huang J G 1995 The structure and property characteristics of amorphous/nanocrystalline silicon produced by ball milling J. Mater. Res. 10 139-48

[4] Dubach A 2005 Microwave heating of silicon powder-the influence of grain size and doping Diploma Thesis (ETH, Zürich)

[5] Khayyat M M O, Hasko D G and Chaudhri M M 2007 Effect of sample temperature on the indentation-induced phase transitions in crystalline silicon J. Appl. Phys. 101083515

[6] Street R A 1991 Hydrogenated Amorphous Silicon (Cambridge Solid State Science Series) ed R W Cahn (Cambridge: Cambridge University Press) p 413

[7] Thompson M J and Tuan H C 1986 Amorphous Si electronic devices and their applications IEEE/IEDM pp 192-5

[8] Concari S B and Buitrago R H 2003 Raman monitoring laser-induced phase transformation in microcrystalline silicon thin films prepared by PECVD Semicond. Sci. Technol. 18 864-9

[9] Gogotsi Y, Baek C and Kirscht F 1999 Raman microspectroscopy study of processing-induced phase transformations and residual stress in silicon Semicond. Sci. Technol. 14 936-44

[10] Vaucher S, Catala-Civera J M, Sarua A, Pomeroy J and Kuball M 2006 Phase selectivity of microwave heating evidenced by Raman spectroscopy J. Appl. Phys. 99113505

[11] Prabakaran R, Kesavamoorthy R and Singh A 2005 Opical and microstructural investigations of porous silicon Bull. Mater. Sci. 28 219-25

[12] Viera G, Huet S and Boufendi L 2001 Crystal size and temperature measurements in nanostructured silicon using Raman spectroscopy J. Appl. Phys. 90 4175-83 